\title{
A narrative approach to explore grief experiences and treatment adherence in people with chronic pain after participation in a pain-management program: a 6-year follow-up study
}

\author{
This article was published in the following Dove Press journal: \\ Patient Preference and Adherence \\ 8 August 2013 \\ Number of times this article has been viewed
}

\author{
Elin Dysvik' \\ Gerd Karin Natvig ${ }^{2}$ \\ Bodil Furnes ${ }^{3}$ \\ 'Faculty of Social Sciences, \\ Department of Health Studies, \\ University of Stavanger, Stavanger, \\ Norway; ${ }^{2}$ Faculty of Medicine and \\ Dentistry, Department of Global \\ Public Health and Primary Care, \\ University of Bergen, Norway; \\ ${ }^{3}$ Faculty of Social Sciences, \\ Department of Health Studies, \\ University of Stavanger, \\ Stavanger, Norway
}

Objective: The aim of this study was to explore grief caused by chronic pain and treatment adherence, and how these experiences are integrated into ongoing life stories.

Methods: A 6-year follow-up using a qualitative mixed-methods design based on written narratives and image narratives was performed. Five women suffering from chronic pain comprised the purposive sample. They had completed an 8-week group pain-management program with two follow-ups, and thereafter continued as a self-help group. A narrative approach was used to analyze the written and image narratives guided by three analytic steps.

Results: Findings showed that experiences of grief over time were commonly associated with chronic pain. The participants' past experiences reflected their grief at having to abandon jobs and social networks, and revealed loneliness and despair. The present life situation seemed to reflect adaptation, and hope for the future had been established. Overall, forward progression means an ongoing struggle towards a reintegrated body and a meaningful life.

Conclusion: Through such narratives, health-care workers can identify treatment adherence related to grief and pain, and learn how people might regain their lives beyond using traditional interviews.

Keywords: chronic pain, follow-up, grief, image, narrative, nursing

\section{Introduction}

Prevalence studies indicate that chronic pain is a severe and frequent health-care problem worldwide, causing human suffering and various other health-care problems. ${ }^{1}$ Chronic pain is described as a multidimensional experience that involves both psychosocial and physiological processes. ${ }^{2}$ The cognitive behavioral perspective is concerned with influencing the motivational, affective, and cognitive aspects of chronic pain and treating some of the factors that may interact with physical pathology and maintain disability. ${ }^{3}$ Ferrell and Coyle ${ }^{4}$ noted that grief is a dimension of these processes and is closely linked to pain. Grief caused by chronic pain can be considered a personal and fundamental experience that carries many meanings, and includes emotional, cognitive, behavioral, and bodily manifestations and expressions. ${ }^{5}$ People tend to endure health problems like chronic pain by suppressing their emotions until they can acknowledge their losses and suffer emotionally. ${ }^{6}$ Experiencing and handling such situations may be described as challenging movements between relearning the world on the one hand and adaptation on the other so that the self is reintegrated. ${ }^{5}$ Assistance is often required from a multidisciplinary team using several approaches based on cognitive behavioral
Faculty of Social Sciences, Department of Health Studies, University of Stavanger, $\mathrm{N}-4036$ Stavanger, Norway

Tel +47 5 I83 4l97

Fax $+475 \quad$ I83 I550

Email elin.dysvik@uis.no 
therapy (CBT). ${ }^{3,7-11} \mathrm{CBT}$ can be defined as interventions that use psychological principles to change behavior, thoughts, and feelings of persons with chronic pain. ${ }^{9}$ Generally, such programs are found to be effective, although differences across studies in treatment and assessment methods seem to produce varied results. Several factors that may play an important role in adjustment are described, like increased ability to control pain, decreased perceptions of disability and harm beliefs, and increased orientation towards selfmanagement. ${ }^{9-11}$ Furthermore, the ability to exert control over the pain situation has been found to mediate the paindepression relationship. ${ }^{12}$

\section{Aim}

The aim of this study was to explore grief caused by chronic pain and treatment adherence and how these experiences are integrated into ongoing life stories.

\section{Theoretical framework}

The term "narrative" has many meanings and is used by researchers in different ways. A narrative is what human beings use to document the passage of time; telling a story creates a beginning, a middle, and an end. ${ }^{13}$ According to Bruner, ${ }^{14}$ meaning is constructed narratively and is a way of connecting past, present, and future. Riessman ${ }^{15}$ indicated that in everyday storytelling, a speaker connects events into a sequence that has consequences for his/her later actions and for the meaning that the speaker wishes to transmit to his/her listeners. Metaphors that appear in illness narratives are internal and clear expressions of personal health and may enhance the understanding of the patient. ${ }^{16}$

Narratives have always been an important source of knowledge in nursing care. ${ }^{17}$ It has been suggested that a narrative approach is particularly useful in work with patients suffering from chronic pain, because the source of their pain is complex and may only be understood through telling. ${ }^{18}$ A narrative approach is also consistent with multidisciplinary and holistic thinking in pain. ${ }^{19}$ Patients talk about their illnesses to health-care workers, family, and friends, creating stories that alter with different audiences. Thus, narratives may also shape and document their changing relationships to chronic pain. ${ }^{19}$

Narrative research has relied on spoken and written interview transcripts. However, words are only one form of communication within this tradition. Other forms, such as images, precede words and can communicate meaning throughout life. Therefore, they are also incorporated into narrative research. ${ }^{15}$ Rose ${ }^{20}$ suggested that working with images can make the interpretation "thicker" and describes aspects that allow the images to be culturally meaningful. Based on these definitions and considerations, a narrative within the context of this study constitutes a specific kind of events organized as stories about health from written reports and images, with specific focus on grief and grief processes in chronic pain.

Researchers have indicated that many studies use pain drawings, such as body charts, ${ }^{21,22}$ and images such as computed tomography scans. ${ }^{23}$ Despite the vast literature on suffering chronic pain, little research has been conducted from a qualitative mixed-methods perspective that includes narratives and images. Moreover, although chronic pain has been widely studied in terms of its origin, treatment, and outcomes, there has been limited research into the relationship between chronic pain and grief, ${ }^{5}$ change processes, and follow-up. ${ }^{8} \mathrm{To}$ address fully and holistically the needs of people living with this problem, we believe that a narrative approach, in which both written reports and images are used, may shed further light on chronic pain and grief beyond traditional interviews, and may allow us to better grasp individuals' stories.

\section{Methods and materials Design}

A qualitative mixed-methods design based on written narratives and image narratives was used to explore phenomena related to grief and pain. Narrative health knowledge constitutes qualitative data. ${ }^{24}$ "Mixed-methods design" refers to the use of two research methods in a single study, when one of the methods is considered incomplete in itself, ie, a qualitative core component with a simultaneous qualitative supplementary component expected to expand the perspective of the core component. ${ }^{25}$ In the "result narrative," the core component forms the base of the results and the supplementary component adds information to special areas of the findings. The design of this study was chosen as we wanted to explore and reveal different experiences of a complex phenomenon like chronic pain in a broader perspective beyond traditional interviews, ${ }^{26}$ and thereby broaden the empirical scope by integrating images ${ }^{20}$ and narratives. ${ }^{15}$ The design is shown graphically in Figure 1.

\section{Participants}

A purposive sample of five women who had completed an 8 -week group pain-management program with follow-up after 6 and 12 months $^{7,8}$ was used. This program structure, based 


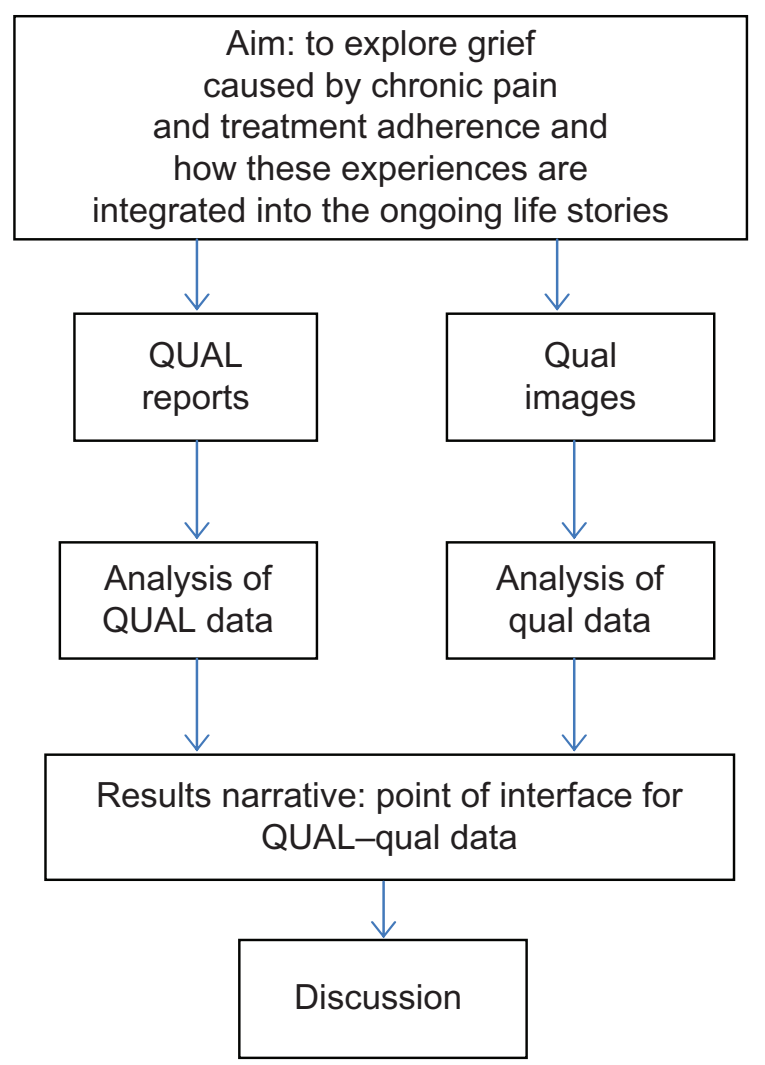

Figure I Schematic overview of the qualitative mixed-methods design, to reveal and compare changes. The left pathway illustrates the core component of the project (QUAL data from the written reports). The right pathway illustrates the supplemental components of the project (qual data from the images). The point of interface is the position at which the core and the supplemental components meet. The "results narrative" refers to the write-up of the core-component findings with the addition of the results of the supplemental components.

on CBT, consisted of supervised dialogue, physical activity, and education. Each session was given once a week in a rehabilitation unit and lasted for 5 hours. After the program finished, these participants continued to meet four times a year on their own as a self-help group. Because they naturally constituted a subgroup in need of a longer follow-up period, and had experienced the same phenomenon, they were able to describe how chronic pain had affected their lives.

The participants received both verbal and written information about the study. They were assured that they were free to withdraw from it at any time and that the data would be treated confidentially. Should any problem occur, it would be addressed by a professional team. Ethics committee approval was obtained from the regional ethical committee and the data inspectorate.

\section{Data collection}

The participants were invited to share their individual stories about living with chronic pain as written reports and images to deepen expressions of the phenomena under investigation. The rationale of and theoretical lens for the questions were based on a holistic understanding of chronic pain, recent grief theory, and narrative understanding. The participants were encouraged to write openly and spontaneously, with no concern for length, grammar, or punctuation. Concerning their drawings, the participants were encouraged to use their own drawing style, to be honest, and to illustrate what spontaneously occurred to them. The following story title was suggested: "A story about grief and grief processes related to living with chronic pain," and several areas were suggested to indicate what they could incorporate:

- Please reflect on the past and try to describe your experiences of grief caused by chronic pain and the ways you have coped with it until today.

- Express examples of grief experiences with which you have dealt.

- Please discuss where you are headed now, and your future expectations.

- Please try to draw your pain and grief experiences.

Two participants sent additional reports to supplement their original narratives.

\section{Data analysis}

The narrative analysis used was case-centered and referred to a family of methods for interpreting a text that has a story form. Major forms are thematic analysis focusing on content, and structure analysis focusing on organization, which can be combined, ${ }^{15}$ and the former was mainly used in this study. As there is no standard approach to narrative analysis, we drew quite flexibility upon the work of several narrative researchers. ${ }^{15,20,27,28}$ Three analytical steps were used when analyzing the data.

In the first step, the written narratives were read openly to get an overall impression of each woman's story. Content, ordering of events, plots, turning points, and metaphors were identified. According to Lieblich et al, ${ }^{27}$ written narratives are analyzed to identify important subtext (1), definition of content categories (2), and formulating the picture of the content universe (3), paying attention to commonalities, differences, and areas of emphasis (Table 1). These analytic steps were performed independently by the first and third authors by moving from the subtext to the content universe and theoretical understanding. Thereafter, consensus was made by discussion and reflection. 
Table I Analysis of the written narratives

\begin{tabular}{lll}
\hline Selection of subtext & Content categories & Picture of the content universe \\
\hline Grief caused lack of energy and fatigue & Past life experiences & Progress and an ongoing struggle \\
$\begin{array}{l}\text { Frustration and despair because of lack of understanding of the body and lack of self } \\
\text { My pain, invisible to others, caused many problems, chaos, and reduced self-esteem }\end{array}$ & $\begin{array}{l}\text { indicate many losses } \\
\text { and grief }\end{array}$ & $\begin{array}{l}\text { towards a reintegrated body and a } \\
\text { meaningful life }\end{array}$
\end{tabular}

Lack of energy, lack of self and meaning in life

The pain has stolen from me the roles of mother, wife, friend, and work colleague

My quality of life is best if I can conserve energy

I still become tired and sorry, but it is not grief

I am aware that I cannot be as social as before

My focus is now on positive aspects and playing an active role

My view of life tells me that I am unique and valuable; acceptance and frequent use of tools

I am positive, aware of my own responsibilities, and I know that I must work

with me all my life

My plans correspond to my present life and are much better than before

I must change my attitude to myself away from my life as it was before,

and work with acceptance

I can do more myself, and am aware of my potential

I must be realistic and make the best of it

Notes: Examples of how the stories were analyzed to identify important subtext, content categories, and picture of the content universe, paying attention to commonalities, differences, and areas of emphasis.

Step two dealt with the interpretation of the visual images (illustrated in Table 2), and the following points in the guidelines were used to approach the complexity and richness of such data: ${ }^{20}$

1. Production. Here, we considered how the image was made, being aware that the circumstances of its production can contribute to the effect achieved by the image.

Table 2 Analysis of the pain drawings

\author{
Present life experiences \\ of the situation indicate \\ movement toward \\ acceptance and \\ adaptation
}

Awareness of their

own potential, and future

plans are optimistic,

but realistic
2. Image. The focus here was on what the image looked like, with specific attention to the composition and social conditions, which play an important role.

3. "Audiencing." Here, the response to the image was written, and the meaning was renegotiated by the authors to justify our interpretation.

Each of these aspects was considered in terms of technological, compositional, and social properties. ${ }^{20}$

\begin{tabular}{|c|c|c|c|}
\hline $\mathbf{P}$ & Production & Image & “Audiencing" \\
\hline I & $\begin{array}{l}\text { Naïve, colored, instrumental, } \\
\text { several illustrations, A4 format }\end{array}$ & $\begin{array}{l}\text { First aid kit, arrows, boxing glove, weight, } \\
\text { tools, handlebar }\end{array}$ & $\begin{array}{l}\text { A battle with ups and downs to find control and } \\
\text { balance; different tools are needed }\end{array}$ \\
\hline 2 & $\begin{array}{l}\text { Naïve, simple, black pencil, } \\
\text { few illustrations, A4 format }\end{array}$ & $\begin{array}{l}\text { Sun shining on a tree, raining? A broken, } \\
\text { nearly invisible flower on the ground; } \\
\text { the shadow from the tree falls on it? }\end{array}$ & $\begin{array}{l}\text { The self as a broken flower, small compared } \\
\text { with the mighty tree, which receives most of the } \\
\text { sunlight; contradictions, the good life in growth }\end{array}$ \\
\hline 3 & $\begin{array}{l}\text { Abstract and concrete body chart, } \\
\text { colored, streamlined, circles and lines } \\
\text { illustrate the content, A4 format }\end{array}$ & $\begin{array}{l}\text { The body with separate parts, head, } \\
\text { thorax and arms, abdomen, and legs }\end{array}$ & $\begin{array}{l}\text { Body-mind separation, different intensities of } \\
\text { pain, feelings, and thoughts fill the separate parts } \\
\text { of the body. Does not work as an entity }\end{array}$ \\
\hline 4 & $\begin{array}{l}\text { Naive, colored, several illustrations, } \\
\text { supplemented with written text, } \\
\text { A4 format }\end{array}$ & $\begin{array}{l}\text { Three people, a woman with a bleeding heart and } \\
\text { tears, another carrying a child, a person surrounded } \\
\text { by people with intertwined arms; mountains, } \\
\text { a heart with black strikes through it, sun and } \\
\text { a road where hope is written in the lower part }\end{array}$ & $\begin{array}{l}\text { Grief and emotions are illustrated and } \\
\text { contrasted with a future filled with hope }\end{array}$ \\
\hline 5 & $\begin{array}{l}\text { Naïve, very detailed, colored, } \\
\text { chest of drawers, title, A4 format }\end{array}$ & $\begin{array}{l}\text { Five open drawers; on the bottom, only small } \\
\text { black animals are crawling; in the next drawers, } \\
\text { fewer and fewer animals are found together with } \\
\text { flowers, sunshine, palms, tunnel opening } \\
\text { with a candle, music, and many hearts on top }\end{array}$ & $\begin{array}{l}\text { Movements. Adaptation process. The pain is } \\
\text { always present, although love, music, sun, and } \\
\text { palms may reduce its presence }\end{array}$ \\
\hline
\end{tabular}

Notes: Three aspects of the visual analysis of images are illustrated. The first deals with how and when the image was made (production). The second is related to the story that is described (the image itself). The third is the response of the viewers ("audiencing").

Abbreviation: $\mathrm{P}$, participant. 
The most suitable interpretation of the images was based on individual analyses by the first and third authors by moving from "production" to "audiencing." Thereafter, consensus was made by summing up and discussion.

In step three, our two narrative methods meet at the point of interface (Figure 1). ${ }^{26}$ To obtain two different perspectives on the same phenomena, the findings of the analysis of the written narratives and the image narratives were compared for each individual. We tried to identify relationship between different forms of expression, nuances, and complementarity to increase depth of understanding. Through a critical approach, all authors took part in this final discussion, linking the findings together.

\section{Trustworthiness}

To ensure the trustworthiness of the study results, several aspects were evaluated, including credibility and dependability, as suggested by Graneheim and Lundman. ${ }^{28}$ The chosen method for data collection was suitable. The most suitable content categories, abstracted from the subtext of the written narratives and the meaning of the images, were analyzed independently, and then discussed and selected by the authors. The analytical steps can be followed in Tables 1 and 2. Although the narratives were separated because of analytical reasons, they are joined in the "result narrative". Representative quotations from the written narratives were presented to demonstrate richness and authenticity, and to illustrate the similarities and differences within and between the subtext. Moreover, additional information from two participants was received later on, which they felt should complement their stories, and was considered as part of the validation process. We also suggest that the content categories and picture of the content universe as well as the "audiencing" of the image narratives cover the data well. Our interpretation is consistent with the findings of previous research, ${ }^{29}$ which can also be seen as validating the findings and confirming that saturation was achieved. The authors suggest that the transferability of the findings may make them relevant to other patients in similar situations.

\section{Results}

First, background data from the sample are presented. Thereafter, findings of the core qualitative data (written narratives), including quotations and the supplementary qualitative data (image narratives), are described independently. Lastly, the data are mixed in the "result narrative," which refers to the point of interface where these data meet (Figure 1). ${ }^{26}$

\section{Background data}

The study participants ranged in age from 41 to 66 years. All had completed high school or its equivalent. They were drawn from different rural municipalities in the county. They were all married with grown-up children, and three had grandchildren. All had suffered from chronic pain caused by different musculoskeletal disorders for many years and reported pain from different regions. Baseline information indicated that mean severity of pain using the visual analog scale was $70 \mathrm{~mm}$. Mean pain duration from year of diagnosis was 13 years. All used analgesics regularly. They all reported positively that their pain was considered a warning signal indicating the need to make a change. Each of the informants had multiple consultations and was seen by many experts over several years. Two of them had undergone several surgeries for additional health problems. Four received disability pensions, one was a part-time worker, and two worked sporadically as volunteers in a rehabilitation center.

\section{Written narratives}

The written narratives (core component) presented detailed descriptions and great variation in writing styles, ie, in their content, metaphors, turning points, and lengths, while focusing on the participants' experiences of pain and grief. The tones of the narratives varied from hope to hopelessness. The sometimes-chaotic narrative style underlined chaos and frustration. Their past life experiences indicated several life restrictions. Variations in the individual interpretation of their pain situation and origins were prominent. Metaphors like "sinking in quicksand," "body-mind falling apart," "the soul is crying," and "the heart is bleeding" were identified and revealed different experiences of their challenging situation. Different episodes seem to have exacerbated their medical situations. For example, one participant emphasized several times that she had lost a baby during pregnancy, and her experiences came to the surface after she was treated by a physiotherapist. Because the situation for one participant had taken that specific form, she developed a story about having a baby as her symptoms worsened. Another participant referred to childhood experiences and the limitations caused by increasingly limited mobility.

Attending the CBT program clearly represented a turning point for all of them. When we considered their descriptions of present life situations, their increased awareness and a more optimistic tone became apparent as they acknowledged their pain, which had led to a disrupted alliance between plans and capacity. Their present life situations and future 
plans included many similarities, and may indicate that the group had learned from each other and had been welded together over a long period of time. Three content categories were identified with the narrative analysis (Table 1): "Past life experiences indicate many losses and grief"; "Present life experiences of the situation indicate movement toward acceptance and adaptation"; and "Awareness of their own potential, and future plans are optimistic, but realistic." These categories were abstracted into a main theme (picture of the content universe) to give meaning and identity to current experiences: "Forward progression and an ongoing struggle towards a reintegrated body and a meaningful life."

To retain authenticity of the patients' experiences, we selected quotations from the narratives to illustrate the different reported aspects of each subtext. Our findings reveal that the participants' past experiences were dominated by several losses and grief, and assistance seemed to be required. "I was so indescribably tired most of the time." "Felt sad and angry because I did not understand my feelings." "Despair because I saw no solutions despite my attempts." "Everything was chaos in my head." "After living with pain for many years, I was acutely sick and had lost all my energy." "In the end, the pain surrounded my whole life; my self-esteem became indistinct." "To stop working, losing daily contact with colleagues is a great sorrow." "I never thought that my feelings were grief, only thought that I was depressed."

Our major findings regarding the participants' present experiences, described in their narratives, were increased awareness and a shift toward opening up to the joy of life as their limitations seemed to regress/fade into the background. The turning point was clearly related to the program based on CBT that they had attended, which had provided them with various tools that allowed them to move toward adaptation. "Have a nice time together with my grandchildren, but in small rounds." "Getting to know that having grief in my situation was normal was liberating; I got the help I needed and managed to move onwards." "It was liberating to mourn the loss of part of me." "Important to find something you can rebuild, which makes you feel you are yourself." "Accepting that life took a special course was also part of the grieving process." "I have learned to set other priorities, listen to the signals of my body." "The way toward a better life has been through training, walking, fellowship, and living a simpler life." "I did regain myself, got my control back."

An optimistic view of the future was expressed, although there was still a need for continuous work and self-control to achieve success. "I am positive about the future, although I have to work with myself all my life." "I have changed my attitude to myself to get ahead." "I expect that my future will be a good life." "I have hope, because the tools I need are there, although I need to use them more effectively." "I focus on positive aspects of life and what I can manage." "It is important for me to search for the meaning in life, people, and activities that give energy and are fulfilling, and make me well." "I need to spend a lot of time to develop meaningful and feasible activities."

\section{Image narratives}

The five image narratives (supplementary component) with which the participants illustrated their experiences of pain and grief also showed marked variations in the forms of expression. They indicate movements and directions to structure their health condition. Like the written narratives, they contained social aspects, involvement, and understanding about their major concern. Loneliness seemed prominently illustrated in the image narratives in different ways, eg, as the distance between the people or illustrations, or as single isolated objects. Teardrops, sun, tree, boxing glove, broken stem of a flower, separation of body and mind, and hearts may illustrate multiple feelings. Some images were very expressive, detailed, and colored, whereas others were more simplistic, colorless, and abstract. As such, the images illustrated participants' capacity to transform what was previously a private experience to being a shared comprehension of grief experiences in chronic pain. According to analytical steps described by Rose, ${ }^{20}$ the production of the image, the image itself, and "audiencing" are illustrated in Table 2, to show the reader our interpretation and as a background for discussion.

\section{Result narrative}

The findings of the two analysis methods were combined to produce the "result narrative," making a deeper critical interpretation possible. ${ }^{26}$ The "result narrative" refers to the write-up of the core component and the supplementary component, and describes how the participants' identity was maintained and created during times of disorder and changing circumstances caused by chronic pain. They tell stories about special grief experiences in their lives that have caused a break between ideal and reality, self and society. These reveal stories of pain, of grief as pain-related problems, chaos, and an unfriendly world. Moreover, they are stories of personal development and strength that opened up for the future to be different. Participants expressing their experience of grief through written narratives and images, after CBT attendance and thereafter continue in the self-help group, made it possible to deal with grief and move forward towards 
a meaningful life. Our comparison of the individual written narratives and the image narratives showed a great deal of coherence. The important themes in the narratives were clearly recognizable in both forms of expression. When the different sources of data were considered together, the images elicited new perspectives through additional details and emotions, and therefore strengthened the interpretation that could be drawn from the corresponding written narratives.

\section{Discussion}

Narratives tell not only about past experiences but also how individuals give meaning to these as challenges and triumphs are shared. By telling their stories, the participants created a distance that enabled them to see their situation more clearly and opened the way for advanced descriptions of grief experiences and loss as a downward spiral. They seemed to have been at the edge of losing themselves, because they lacked energy and available resources during their daily struggle. The most obvious turning points were related to the moments of clarity achieved when the participants received professional assistance. They learned about the physiology of pain and regulating factors that might decrease as well as increase pain and hinder treatment adherence. Participation in the CBT program and thereafter in the self-help group seems to have had a clear awareness function, and an upward spiral was initiated. This was described as a great help in a period of hopelessness, as a new start, and as a way of getting rid of old baggage and moving on. As such, a process was initiated of what Morse ${ }^{6}$ calls a breaking through from endurance to emotional release with cognitive reorganization: meaningmaking and an optimistic and realistic focus on the future was established. In that way, we see that gaining new insight and writing and drawing in itself might have been helpful. ${ }^{29}$

Grief, as a natural part of chronic pain similar to the grief that follows a traumatic event, was highlighted during the CBT program. This awareness was a thought-provoking process for the participants, and made it easier to handle the situation. To process grieving was identified as another important turning point, which enabled them to look for new possibilities and thereby regain self-control. Our findings support earlier work that demonstrated that living with chronic pain involves relearning and adaptation processes. ${ }^{5}$ Common features expressed in the grieving process were recognized, like moving from despair to hope, from lack of understanding to insight, from meaning disruption to increased meaning, and from bodily discomfort to reintegrated body. ${ }^{5}$

As discussed in the work of Riessman, ${ }^{15}$ sickness is articulated through stories. Although the participants' interpretations of their illnesses were different due to selective reconstruction of the past, each narrator described a complex understanding of her chronic pain, grief, and level of disability. They made sense of their challenging past situations using several metaphors, which enhanced understanding about what the situation was like. As these illness metaphors are indirect expressions of the participants' understanding of their own situation, they may help health-care workers to understand what is confusing and difficult to articulate in a literal form. Different episodes seemed to have worsened their medical and social situations, and were related to family life, own health, and social life. A lack of understanding by outsiders, and loneliness, was reported by all participants, and confirm findings from Skuladottir and Halldorsdottir. ${ }^{30}$ In particular, the participants allowed us to follow their chaotic paths through the social welfare system, and one of the participants felt that the system worked against her.

The participants revealed their different attempts to establish new points of reference between the body, the self, and society, and to reconstruct a sense of order from the fragmentation caused by their chronic pain. Progress means an ongoing struggle towards a reintegrated body and a meaningful life. Through their fight for a better life, they clearly reaffirmed that life has a course and a purpose. This view is also shared by Riessman, ${ }^{15}$ who states that this may be an important focus within a narrative-research method.

The concept of "narrative reconstruction" refers to the imaginative work individuals perform when chronic illness disrupts their expected life courses. Williams argues that beliefs about the causes of misfortune are human interpretative practices, and meet our need to reconstruct narratively the discontinuities in an imagined biography. ${ }^{31}$ Here, the most obvious grief experiences could be identified through a bleeding or a broken heart and tears. More hidden experiences, like body-mind separation and that life had fallen apart, seemed to be closely linked. As such, all images illustrated deep personal changes caused by chronic pain and were related to self, self-esteem, and surroundings. Other ways to understand these images are to view them as representations of conflicting experiences and needs or personal development. This supports earlier findings that grief processes are considered as personal and fundamental experiences that carry many meanings and bodily manifestations. ${ }^{5}$

It has been suggested that the social aspect is the most important modality for understanding the "audiencing" of images. ${ }^{20}$ The separate figures, fragmented by great distances, can be understood as broken bonds or relations to oneself or others that are documented in previous research. ${ }^{30,32}$ Our findings also support the notion made by Carr and colleagues ${ }^{19}$ 
that meeting the needs of individuals in pain necessitates holistic thinking. Included in such help is also the provision of social support and reintegration into society.

In our society, the feminine role as an independent and strong person, managing both family and working lives, is highly valued. For all the informants, the images expressed that their life situations had separated them from life activities in different ways. Several of the participants illustrated their situation as prompting strong feelings of reduced worth, uselessness, and inadequacy. Their fight with society, directed against social norms, as well as the medical system can be identified. These visual representations of experiences revealed strong feelings of grief and despair related to body and soul, indicating that professional help was needed.

To establish a cultural understanding of patients' illness images, it is also necessary to consider the medical practices that diagnose and treat that illness. ${ }^{31}$ Although each of the informants had multiple consultations and was seen by many experts over several years, their situations first seemed to improve after they participated in the CBT program. Illustrations of several tools - first aid kit, boxing glove, weight, and handlebar - are closely linked to basic ideas like taking an active role, understanding of regulating factors that might increase as well as decrease pain, and "self-medication" through use of the bodies' own healing processes.

As the image narratives correspond with the metaphors and descriptions from the written narratives, this may strengthen the interpretation to be drawn. In that way, the combined and supplementary findings have led to deeper understanding about the relationship between chronic pain and grief and treatment adherence in the chronic pain situation. Our findings are consistent with the goal of CBT interventions to help patients experiencing chronic pain to cope more effectively with long-term demands and to improve their quality of life and functioning. ${ }^{3}$ Such programs belong to the psychological tradition, and are also described as body-mind therapies. ${ }^{33}$ To advance the treatment for individuals who live with chronic pain, it seems clear that a multidisciplinary team approach and follow-up are often needed, ${ }^{8-11}$ where grief experiences as an integral part of chronic pain should be highlighted and stimulate treatment adherence. ${ }^{7,8}$

\section{Methodological considerations}

Using two data sources (written narratives and written images) in this manner has several clear advantages over traditional interviews. It allows a more personal, expressive, and detailed description uncovering individual experiences and the researchers' focus of interest. In particular, it can shed light on contradictory meanings and the significance of diverse audience interpretations..$^{20}$ We are aware that image reflects the artist's view and values about what is important. Moreover, our analytical strategies support one possible interpretation, and that different interpretations of the meaning and theoretical position may create different narratives. ${ }^{15,20}$ Once words and images are published, we can only be certain that our narratives will inevitably be infused with various meanings by different audiences. ${ }^{34}$

Although the sample was rather selective and small, the strengths of this study were the richness of the data and that the data were collected from two sources, which broaden the scope of the written narrative. That the sample was composed of women reflects the higher proportion of women attending the CBT program. They were encouraged to focus explicitly on grief experiences, which may have limited their stories. On the other hand, this narrow focus contributed to specific and important knowledge about the topic of interest. Further research is needed, including more informants who have and have not attended a self-help group after CBT, and belonging to both sexes, to explore grief experiences and treatment adherence further using several data sources.

\section{Implications}

As relapse is a common problem in this group of patients, follow-up may reveal long-term results and suggestions for relapse-prevention strategies, such as processing grief. Subsequent changes in the personal narratives cannot be understood simply as a quantitative movement from more to less pain. ${ }^{19}$ Here, a meaningful life does not necessarily mean the elimination of pain, but rather a refusal to let the pain dominate, and the repossession of life, moving step by step from victim to survivor.

We suggest that such narrative information better contextualizes the participants' situation. A failure to understand a patient's past experience of pain, their present status, future plans, and the meaning of his/her pain can diminish a health-care worker's capacity to treat that patient. ${ }^{35}$ Unless the patient tells his/her story, no context exists in which to understand what living with chronic pain means to the patient. Through such storytelling, we can identify grief experiences and treatment adherence and learn how people suffering from chronic pain might regain their lives. As living with chronic pain is a worldwide problem presented in the context of international research, we believe that our findings and suggestions may be of general relevance for nurses engaged in chronic pain management. 


\section{Conclusion}

Participation in the self-help group after completion of the CBT program, and writing and creating images in itself, might have been helpful. We suggest that the use of narratives, incorporated in a mixed-methods design, offers an opportunity to understand the situation of chronic pain more holistically from the perspective of the patient. To advance treatment adherence for individuals who live with chronic pain, it seems clear that grief experiences as an integral part of chronic pain should be highlighted.

\section{Disclosure}

The authors declare no conflicts of interest in this work.

\section{References}

1. McCracken LM. Contextual Cognitive-Behavioral Therapy for Chronic Pain (Progress in Pain Research and Management). Seattle: IASP; 2005;33.

2. Flor H, Turk DC. Chronic Pain: An Integrated Biobehavioral Approach. Seattle: IASP; 2011.

3. Turk DC. Cognitive-behavioral approach to the treatment of chronic pain patients. Reg Anesth Pain Med. 2003;28:573-579.

4. Ferrell BR, Coyle N. The Nature of Suffering and the Goals of Nursing. New York: Oxford University Press; 2008.

5. Furnes B, Dysvik E. Dealing with grief related to loss by death and chronic pain: an integrated theoretical framework. Part I. Patient Prefer Adherence. 2010;4:135-140.

6. Morse J. Towards a praxis theory of suffering. Adv Nurs Sci. 2001;24: 47-59.

7. Dysvik E, Kvaløy JT, Stokkeland R, Natvig GK. The effectiveness of a multidisciplinary pain management programme managing chronic pain on pain perceptions, health-related quality of life and stages of change - a non-randomized controlled study. Int J Nurs Stud. 2010;47: 826-835.

8. Dysvik E, Kvaløy JT, Natvig GK. The effectiveness of an improved multidisciplinary pain management programme: a 6- and 12-month follow-up study. J Adv Nurs. 2011;68(5):1061-1072.

9. McCracken LM, Turk DC. Behavioral and cognitive-behavioral treatment for chronic pain. outcomes, predictors of outcome, and treatment process. Spine. 2002;27:2564-2573.

10. Turner JA, Holtzman S, Mancl L. Mediators, moderators, and predictors of therapeutic change in cognitive-behavioral therapy for chronic pain Pain. 2007;127:276-286.

11. Turk DC, Burwinkle TM. Cognitive-behavioral perspective on chronic pain patients. Crit Rev Phys Rehabil Med. 2006;18:1-38.

12. Okifuji A, Turk DC, Sherman JJ. Evaluation of the relationship between depression and fibromyalgia syndrome: why aren't all patients depressed? J Rheumatol. 2000;27:212-219.

13. Ricoeur P. Time and Narrative. Chicago: University of Chicago Press; $1988 ; 3$.

14. Bruner J. Acts of Meaning. Cambridge: Harvard University Press; 1990.

Patient Preference and Adherence

\section{Publish your work in this journal}

Patient Preference and Adherence is an international, peer-reviewed, open access journal focusing on the growing importance of patient preference and adherence throughout the therapeutic continuum. Patient satisfaction, acceptability, quality of life, compliance, persistence and their role in developing new therapeutic modalities and compounds to
15. Riessman CK. Narrative Methods for the Human Sciences. London: Sage; 2008.

16. Stensland P, Malterud K. Unravelling empowering internal voices - a case study on the interactive use of illness diaries. Fam Pract. 2001;18: 425-429.

17. Vallerand AH, Hasenau SM, Anthony MJ, Saunders M. Pain, suffering, and the uses of narratives in nursing. In: Carr DB, Loeser JD, Morris DB, editors. Narrative Pain and Suffering (Progress in Pain Research and Management). Seattle: IASP; 2005;34:215-225.

18. Charon R. A narrative medicine for pain. In: Carr DB, Loeser JD, Morris DB, editors. Narrative Pain and Suffering (Progress in Pain Research and Management). Seattle: IASP; 2005;34:29-44.

19. Carr DB, Loeser JD, Morris DB. Why narrative? In: Carr DB, Loeser JD, Morris DB, editors. Narrative Pain and Suffering (Progress in Pain Research and Management). Seattle: IASP; 2005;34:3-13.

20. Rose G. Visual Methodologies. London: Sage; 2001.

21. Ohnmeiss D. Repeatability of pain drawings in low back pain population. Spine. 2000;25:980-988.

22. Jamison RJ, Fanciullo GJ, Baird JC. Computerized dynamic assessment of pain: comparison of chronic pain patients and healthy controls. Pain Med. 2004;5:168-177.

23. Tracey I. Taking the narrative out of pain: objectifying pain through brain imaging. In: Carr DB, Loeser JD, Morris DB, editors. Narrative Pain and Suffering (Progress in Pain Research and Management). Seattle: IASP; 2005;34:127-163.

24. Karlberg I, Hallberg LRM, Sarvimäki A. Introduction and aims of the book Health, Public Health and Research on Public Health. In: Hallberg LMR, editor. Qualitative Methods in Public Health Research. Lund, Sweden: Studentlitteratur; 2002:13-38.

25. Morse JM, Niehaus L, Wolfe RR, Wilkins S. The role of the theoretical drive in maintaining validity in mixed-method research. Qual Res Psychol. 2006;3:279-291.

26. Morse JM, Niehaus L. Mixed Method Design: Principles and Procedures. Walnut Creek (CA): Left Coast Press; 2009.

27. Lieblich A, Tuval-Mashiach R, Zilber T. Narrative Research: Reading, Analysis, and Interpretation. Thousand Oaks (CA): Sage; 1998.

28. Graneheim UH, Lundman B. Qualitative content analysis in nursing research: concepts, procedures and measures to achieve trustworthiness. Nurse Educ Today. 2004;24:105-112.

29. Furnes B, Dysvik E. Therapeutic writing and chronic pain: experiences of therapeutic writing in a cognitive behavioural programme for people with chronic pain. J Clin Nurs. 2012;21:3372-3381.

30. Skuladottir H, Halldorsdottir S. The quest for well-being: self-identified needs of women in chronic pain. Scand J Caring Sci. 2011;25:81-91.

31. Williams G. The genesis of chronic illness: narrative re-construction. Sociol Health Illn. 1984;6:175-200.

32. Crowe M, Whitehead L, Gagan MJ, Baxter GD, Pankhurst A, Valledor V. Listening to the body and talking to myself - the impact of chronic lower back pain: a qualitative study. Int J Nurs Stud. 2010;47:586-592.

33. Astin JA. Mind-body therapies for the management of pain. Clin J Pain 2004;20:27-32.

34. Jackson JE. How to narrate chronic pain? The politics of representation. In: Carr DB, Loeser JD, Morris DB, editors. Narrative Pain and Suffering (Progress in Pain Research and Management). Seattle: IASP; 2005;34:229-242.

35. McCaffrey R, Frock TL, Garguilo H. Understanding chronic pain and the mind-body connection. Holist Nurs Pract. 2003;17(6):281-287.

\section{Dovepress}

optimize clinical outcomes for existing disease states are major areas of interest. This journal has been accepted for indexing on PubMed Central. The manuscript management system is completely online and includes a very quick and fair peer-review system. Visit http://www.dovepress.com/ testimonials.php to read real quotes from published authors. 